
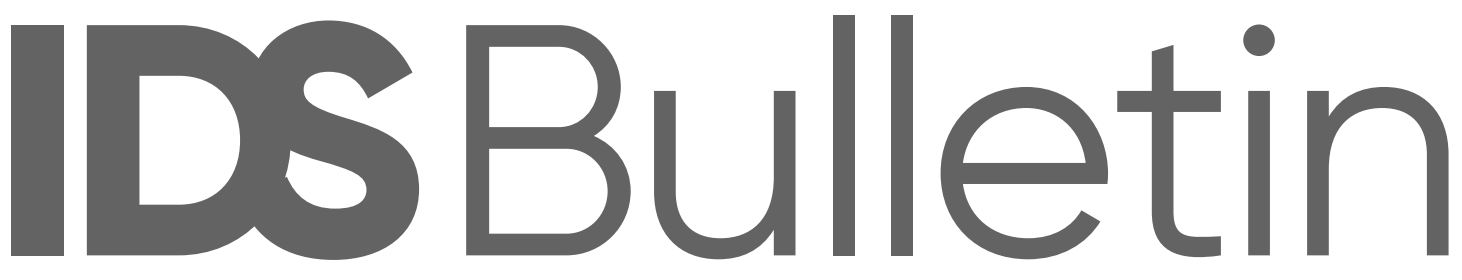

Transforming Development Knowledge

Volume 51 | Number 2 | September 2020

\title{
COLLECTIVE ACTION FOR ACCOUNTABILITY ON SEXUAL HARASSMENT: GLOBAL PERSPECTIVES
}

Editors Mariz Tadros and Jenny Edwards

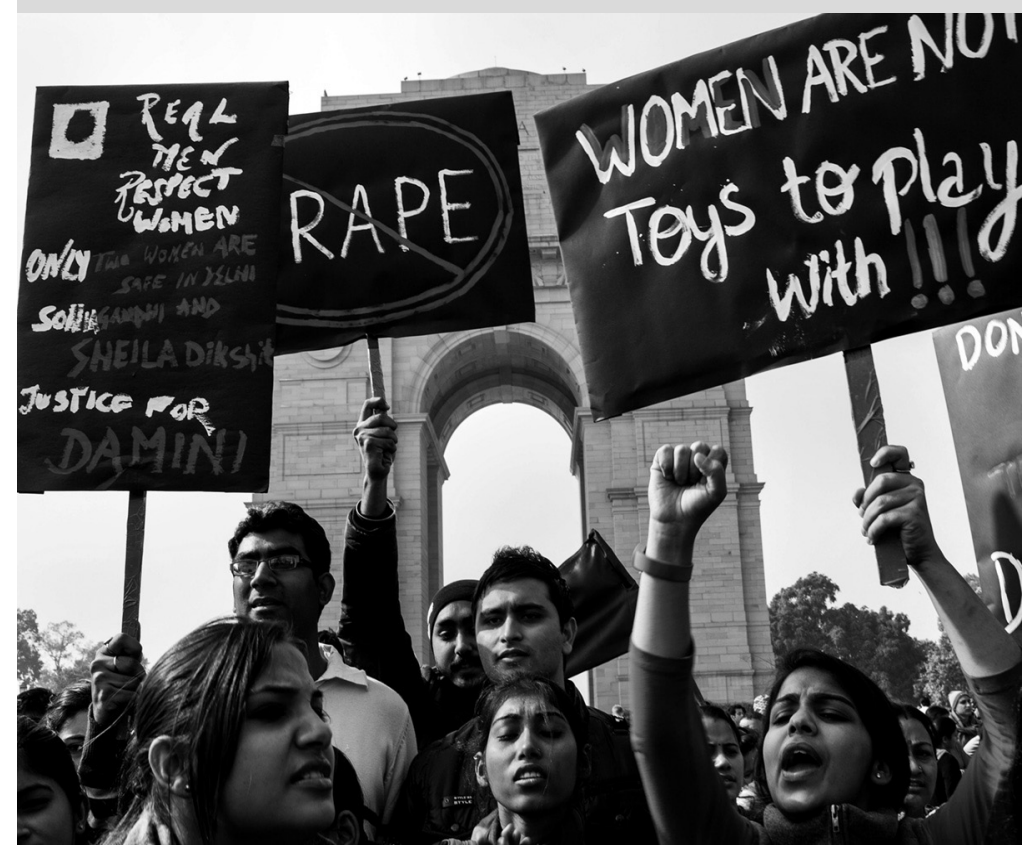


Notes on Contributors

Collective Struggles Against Sexual Harassment: What We Have Learnt About Pathways to Accountability and their Outcomes Mariz Tadros and Jenny Edwards

Fighting Sexual Harassment on Campus: How Local Contexts of Different Universities Affect the Dynamics and Outcome of these Efforts Amal Hamada, Ahmed Kheir, Enas Hamdy and Heba Youssif

Women Politicians Navigating the 'Hostile Environment' in Pakistan Ayesha Khan, Zonia Yousuf and Sana Naqvi

'Me Too' and the 'List' - Power Dynamics, Shame, and Accountability in Indian Academia

Adrija Dey

Multilevel Responses to Sexual Violence in Schools in West Africa Jordan J. Steiner and Anne M. Spear

Uniting Against the Tides: Filipino 'Shefarers' Organising Against Sexual Harassment

Lucia Tangi

Disruption and Design: Crowdmapping Young Women's Experience in Cities Sophie Tanner, Nicole Kalms, Hayley Cull, Gill Matthewson and Anthony Aisenberg

Collective Silence and Accountability for Sexual Harassment in Lebanon Menaal Munshey

Accountability with Teeth

Maha El Said

Glossary 


\title{
Multilevel Responses to Sexual Violence in Schools in West Africa" ${ }^{+}$
}

\author{
Jordan J. Steiner ${ }^{1}$ and Anne M. Spear ${ }^{2}$
}

\begin{abstract}
With growing recognition of sexual and gender-based violence (SGBV) occurring in schools, the governments of Burkina Faso and Benin, partnered with non-governmental organisations (NGOs), have attempted to implement systems of response within the school environment. This empirical study applied the socioecological framework to highlight the intersecting relationship of multiple contexts within society including the interpersonal, family, community, school, and national identities. The findings revealed inadequacies and possibilities for holistic action and accountability in both countries. Data were analysed from qualitative interviews with Beninese and Burkinabe government ministries, international and local NGOs, and community organisations. Barriers exposed complex difficulties in holding perpetrators accountable and sustainably moving towards collective action as a result of entrenched gender dynamics and social norms. However, there are pockets of action to protect victims and hold perpetrators responsible through considering communitarian ideals in addition to official policies. This study offers insight into two nations struggling to develop contextual responses of possibility.
\end{abstract}

Keywords sub-Saharan Africa, Burkina Faso, Benin, sexual and gender-based violence, schools, multilevel response.

\section{Introduction}

Victims of sexual and gender-based violence (SGBV) are starting to be recognised in educational institutions and are now seeing their perpetrators held accountable for their crimes in many places around the world. Sexual violence in this context can include unwanted sexual comments, touching, harassment, forced sex, rape, coercive behaviours such as pressure for sexual favours, and transactional sex. Perpetrators of this violence can include teachers, students, administrators, and community members (Dunne, Humphreys and Leach 2006; Lee et al. 1996; UNGEI 2018). However, in Benin and Burkina Faso, victims are often not heard 
in relation to SGBV (Antonowicz 2010; Diawara et al. 2013). This article explores why the silence remains around SGBV in schools in these two countries and how different levels of society are responding to the violence.

The stigmatised phenomenon, while documented in both Benin and Burkina Faso (Devers et al. 2012; Zare, Yaro and Dan-Koma 2008), continues to be covered in veils of silence, perpetuating a culture of lack of accountability. For example, studies in Benin found that three quarters of adolescent girls report some form of sexual violation from teachers, and that 80 per cent of girls knew of students approached by teachers for sex (Akpo 2008; La Nouvelle Tribune 2018a; Wible 2004). In Burkina Faso, physical and sexual violence and harassment against girls and women were found to be commonplace, and accepted as normal, in every aspect of society (Forsyth-Queen, Gonzalez and Meehan 2015; Zare et al. 2008). From a study of pregnant schoolgirls, 10 per cent reported getting pregnant by their teachers (Diawara et al. 2013). Despite being a common phenomenon in both countries, there is a dearth of sufficient, peer-reviewed research on this subject.

Both Benin and Burkina Faso have worked with the international community, such as the United States Agency for International Development (USAID) and Plan International to incorporate policies and laws aligned with the Sustainable Development Goals (SDGs) to increase girls' enrolment and completion of secondary school education, provide safe schooling, and decrease unwanted teenage pregnancy. However, this article highlights how the current response is inadequate for the nature of the phenomenon in West Africa and does not fully consider social norms that create barriers to enforcement of laws and implementation of policies, or consider a holistic, communitarian response.

\section{Current responses}

Collective action, often found in social movements, generates success in implementing policy change when movements are able to raise awareness among the masses towards the social problem, develop links to privileged networks to influence key decision makers, and organise a critical mass of people to take committed and sustained action (Novelli 2010). With past feminist mobilisation globally, collective action has occurred out of state capacity and institutional legacies (Weldon and Htun 2013). In Benin and Burkina Faso, past mobilisation against sexual violence in schools within the last decade lacked a critical mass, while small-scale grass-roots efforts were often assisted and defined by transnational agencies. International policy agendas, such as the UN Declaration on the Elimination of Violence Against Women (UN General Assembly 1993), and most recently SDG 5, focusing on the elimination of violence against girls and women (Hughes 2017) have driven many of the government programmes and law reform, but have not led to social movements in which a large organised group of citizens demand change. 
Rather than an authentic social movement organised at the grass-roots level, government action such as policies and laws has often come after international non-governmental organisations (INGOs) have given funds to pressure the government into addressing the social issues. In Benin, the beginnings of collective action came out of conferences and workshops with young girls across the country organised by Women in Law and Development in Africa (WiLDAF) Benin and the National Network for the Promotion of Girls' Education. This led to 2006 legislation addressing sexual harassment in schools, punishing perpetrators with fines and imprisonment (République du Bénin Assemblée Nationale 2006; Séne 2010). Moreover, aided by USAID and WiLDAF advocacy (Arnoff et al. 2013), in 2012, a more comprehensive law was passed bringing a multidisciplinary response to violence against women, including prevention, protection, and punishment in education, work, and family life (Hughes 2017; République du Bénin Assemblée Nationale 2012). In the absence of sufficient government funding, INGOs and UN agencies have supported the implementation of laws and policies including school-based prevention programmes, and service provision, such as One Stop Centres, that still remain severely underfunded (Hughes 2017).

Similar limited actions have occurred in Burkina Faso. Policies have emerged from the traditional pressure applied by INGOs and NGOs within the country. For example, in 2018, the National Assembly passed a law that prohibits teachers from having sexual relationships with students under the age of 18 . While this new law that directly named teachers is known in the education sector, most policies around combating SGBV in schools are unknown. For example, the National Strategy for the Acceleration of Girls' Education (SNAEF) 2012-2021 (Government of Burkina Faso 2012), targeted to reduce violence against girls in schools by 50 per cent by 2021, is not widely known, nor is there any visible evidence that the systems proposed in the action plan have been implemented (ibid.). This indicates an absence of pressure from local, organised groups to hold the government accountable for following through on policies, strategies, and laws.

Although there are recent policies and laws responding to the violence, the lack of enforcement demonstrates a lack of commitment to addressing SGBV. Research has found that social norms appear to trump international pressure in Benin and Burkina Faso, and are perpetuated by a systematic oppression of women through barriers to implementation, by men responsible for implementing the law, corruption related to familial ties, and traditional, religious, and ancestral leaders who may in part encourage gender inequality and inhibit state-led implementation (Hughes 2017; Spear 2018). 


\section{The nature of collective action at different levels of society}

This article highlights the intersecting relationship of multiple contexts within society using a multi-tiered socioecological theory of the World Health Organization (WHO) model on violence (WHO 2002). This framework offers a unique lens to understand the pervasiveness of gender oppression that creates an environment for SGBV as well as obstacles to stopping such violence at multiple levels (Cowie and Dawn 2007a). This framework has also recently been applied to minimum standards to prevent SGBV globally (UNGEI 2018). The results of this study are presented at different levels to demonstrate the rooted complexity of social norms that include gender inequalities entrenched at each level. In examining the data using the ecological theory, hidden pockets of collective action, resistance, or responses to combating the violence are explored, with a call for engaging key stakeholders and various audiences, while exploring, through a different lens, the obstacles to collective movements. This allows for an analysis that acknowledges the interactive spheres of influence (Meinck et al. 2015) between the individual, interpersonal community, and societal levels, and the possibilities of holistic response.

\section{Methodology}

A qualitative approach was used to gather and analyse data from interviews with key stakeholders. Data for this study were generated from 38 semi-structured interviews (24 in Benin and 14 in Burkina Faso) with participants from government ministries, INGOs, local NGOs, and community organisations in July 2016. The interviews in Benin were conducted in the commercial capital of Cotonou, as well as semi-urban environments in the north and west of the country. In Burkina Faso, interviews took place in Ouagadougou, as well as in the north and east regions of the country. Interview questions included themes related to the nature of relationships between male teachers and adolescent girls, the nature of consent, the impacts of these relationships, and challenges and successes in response and prevention. Participants were recruited and enrolled to the study through purposive and snowball sampling. All interviews were conducted in French by the authors and then translated into English. Data analysis involved developing codes into families and overarching themes.

\section{Findings \\ 5.1 Individual}

The individual level demonstrates intrapersonal understandings and individual attitudes embedded within larger constructs (Cowie and Dawn 2007a) that can increase the likelihood of becoming a victim of violence through these risk factors (CDC 2015). This is embedded within gendered norms that impose stigma and shame upon survivors (McCleary-Sills et al. 2016). In the analysis at the individual level within this framework, this is not in order to place responsibility or blame, but rather 
to demonstrate harmful victim blaming or placing undue responsibility on the victim to pursue justice. In this section, we explore the theme of individual responsibility of the victim to hold their attacker accountable.

Victim's disclosure: Participants hinted at students' fear of breaking the social code of silence in order to protect themselves from being ostracised. For example, the head of a commune-level social service centre in Benin explained that 'girls do not complain... during awareness raisings, we educate students to denounce... but they think the teachers have a lot of power... or it is in the family... people have fear... in the schools, there are no statistics.' In Burkina Faso, the president of a local community association similarly articulated that 'if you do not want to have problems, you'll be silent. So, the idea of denouncing them is all well and good, but usually she does not dare to do it.'

Both countries demonstrate examples of victims' ongoing fear of disclosure of sexual violence, which may hinder the ability to hold predators accountable as well as to develop local movements to combat such violence. INGO programmes focus heavily on training individual bystanders and victims to go to the authorities to report SGBV. Policies offer protection for victims and have systems of reporting; however, these policies are not enforced. Rather, social norms that adhere to fear and stigma continue to be an obstacle for reporting cases of sexual violence and harassment.

\subsection{Interpersonal}

This level considers the manner in which adults and young people communicate, and how these interactions may lead to parents and other adults aiding victims in denouncing perpetrators (Cowie and Dawn 2007a). It is at this level that social movements in both countries have focused their work. For example, the female high school teachers who formed the local association Association for the Promotion of Girls and Women (Association Pour le Promotion de les Filles et les Femmes - APEFF) in Burkina Faso often disregard the systems of reporting set up through official policies, but rather combat violence at the interpersonal level. This is in line with social and cultural norms of West African societies, where resolutions are found through informal systems at the intrapersonal level, preserving relationships.

Parents: Parents appear to enforce social norms of silence and shame victims by refusing to report violence or support the child. For example, a representative at the Ministry of Youth and Adolescents in Benin articulated,

The family is more reticent of reacting to incidents of violence... They choose and like to deal with issues at home... for the case of rape... it is shameful for the family... therefore, there is often an exchange of money between the family. 
In Burkina Faso, a female INGO employee added: 'Parents are often complicit. They themselves do not believe the girl or want to report [sexual violence].' However, parent associations provide an opportunity for possible collective action. The role of women and mothers are noted as key to supporting their children, assuming they would be more willing to combat the silence and stigma against victims. A representative of an INGO in Benin articulates:

The parents' associations are dominated by men... women's opinions were not considered by the men... Parents' associations in the past were more important... but Association des Mères Éducatrices [AME] [mothers' associations] have become more important... but only Association des Peres Éducatrices [fathers' associations] gets money from the government.

An NGO representative in Burkina Faso further explains this possibility: 'When mothers have the means they will choose to educate all their children. So, we support the income-generating activities of the AME.' The role of parents does not appear to be helpful in reporting violence that occurs; however, mothers do continue to be thought of as a potential protective factor.

Teachers: Teachers are often tasked with preventing and responding to violence in schools. However, the normalisation of predatory behaviour and abuse of power is present. In Benin, a National Inspector of Schools described: 'For teachers, a girl should not refuse... it's a shame for them... it becomes a challenge that you have to take.' A government official working on gender issues in the Ministry of Education in Burkina Faso further explains:

It can be cases of sexual harassment, by teachers, not all though, who abuse or influence girls; something like, if you want to better understand the course, come to my place. Once there, he abuses the student. This teacher can give the student these explanations as promised or not but gives her good grades. We call it sexually transmitted grades.

The difficulties girls encounter in rejecting sexual advances are often due to the transactional nature of sexual interactions in the Benin and Burkinabe context, resulting from unequal power dynamics. Teachers are acknowledged as sexual predators in both Benin and Burkina Faso. However, what is not directly mentioned is that school colleagues may know what occurs and stay silent, as noted within several interviews with teachers, where colleagues do not report the behaviour, citing fear for their jobs and wellbeing.

The role of boys: Several participants spoke of the culpability of male students and their entrenchment in sexual practices between teachers and girls. A Beninese NGO representative explained: 'It is difficult for the teacher if there is not an 
intermediary. They must create a situation for exchange... it is the teacher who profits... it is the boys who look for good notes.' In Burkina Faso, the role of boys was discussed not as intermediary for male teachers but as predators themselves. Participants acknowledged the destructive masculinity that boys are socialised to enact. The president of a local association stated:

In the family, the boy must be turbulent, he must be aggressive... So then, for no reason at all he wants to fight and perhaps he encounters a girl on the route to school... there is nothing she can do to avoid it. If you take a class with a girl and she refuses you, you must beat her.

Boys in both countries, although manifesting differently in each context, are discussed as either assisting possibilities of sexual violence and exploitation or partaking in the normalisation of their role as predators themselves. The role and complexities of parents, teachers, and boys contribute to the lack of collective action illustrated by the normalisation of violence, oppression, and silence.

\subsection{Community}

At this level, systematic influences (Cowie and Dawn 2007a) are critical in understanding the role of violence in a society, based on how community networks respond. Benin and Burkina Faso have worked to develop the infrastructure that supports combating SGBV and allows for the implementation of laws. However, participants in this study stated that reporting and response does not happen at the community level.

Social services: Disinvestment in social services provides an example of the lack of sufficient state commitment to responding to incidences of violence and to the implementation of legislation, therefore hindering action by eliminating a space for victims and advocates to report violence. A representative at a Beninese Social Service Centre at the department level illustrates that:

The director is not always free to listen... and there are only two social workers at the department level of social service... I, myself do all the awareness raising for the department... there are not enough therapists to listen... there is not enough money.

Furthermore, in Burkina Faso, a government official, tasked with implementing trainings, reiterated: 'As I told you, we do not have the resources to carry out our actions plan [sic].' In both Benin and Burkina Faso, community support is weakened by lack of state capacity and resources to social services, where justice could be preserved, perpetrators held accountable, and victims protected.

Impunity: In both countries, cultural and societal norms related to shame, male privilege, and preference for handling things 
privately in the home or between families allows for a lack of accountability and legal enforcement. For example, a local Beninese NGO representative stated: 'Without punishment, people continue... there are certain situations that there is compliance, but also not... there is the situation where the police are very close to the teacher...'. In Burkina Faso, the female president of a local Burkinabe association articulated: 'It is really quite serious and while we have to go to the police about it, often it is the police who bring these girls to be married.' Additionally, a regional minister from the Ministry of Education in Burkina Faso, stated: 'All these [types of violence] exist but it is not reported. The culture of accountability is not present in our minds.' According to the participants, those responsible for enforcing accountability at the local and regional levels often are complicit or do not take action, illustrating impunity.

\subsection{Societal}

This level relates to the wider society including social and cultural norms that might support violence through economic and social policies and inequalities (Cowie and Dawn 2007a). This helps maintain a climate in which violence is either encouraged or inhibited, and in maintaining economic or social inequalities between groups (CDC 2015). It is at this level that national laws and policies are created and where enforcement is centred.

Laws: The laws responding to sexual violence in each country are often vague and not implemented or enforced, as mentioned earlier. For example, a former Beninese secondary school teacher and NGO worker explained, in response to the 2012 law against violence: 'The law is not applied. The people do not know the law. The NGOs do not raise awareness. It exists, but they do not know it.' Moreover, in Burkina Faso, a Burkinabe INGO representative illustrated that:

The law forbids [forced marriage and rape] because the Family Law is very clear. There is no right to marry a minor child, that is clear. We do not have the right to force because you must ask for consent. So, these acts are condemned [by law], but as it is cultural, people do not want to denounce violations.

Both Benin and Burkina Faso provide evidence of laws, often that emerged from the beginnings of collective action, that are completely stymied by lack of enforcement and cultural shame. National stakeholders did not demonstrate critical reflection on the limitation of the laws, or what is needed to challenge and ultimately alter the social norms of silence with their deeply entrenched marginalisation of girls and women that encourages impunity. All reported the existence of the violence, talked of the phenomenon, and affirmed the ill consequences endured by victims. Nevertheless, despite much proposed action, few responses are occurring. Thus, impunity continues to be the norm at the community and societal levels. 


\section{Accountability}

While there may be pockets of resistance via actions towards policies, national studies, and small-scale awareness campaigns, this research shows that there was an inability or unwillingness to take effective action to combat sexual violence across all levels. At the national level, there was no evidence provided by participants in either country that existing policies were effectively implemented by individuals, groups such as teachers or parents, or at the community level. There was also no systematic mechanism for reporting, almost guaranteeing that denouncing crimes of a sexual nature will not happen. Lawmakers and organisational influencers themselves admit that laws are not enforced, perhaps partly due to the lack of structured reporting mechanisms, which despite being written into policies and action plans, have not yet been implemented. This major shortcoming renders laws ineffective at combating sexual violence, supports the social norms of silence, and helps avoid accountability.

When national responses are absent or lack the strength to protect citizens, grass-roots organisations can mobilise to apply pressure for systematic change (Weldon and Htun 2013). However, at the local and regional levels in both countries, collective action is lacking to place substantial pressure on government agencies, schools, or other community institutions to protect victims or potential victims. Sustainable accountability is avoided as a result of entrenched gender oppression, and an inability to effectively hold perpetrators accountable as a result of social norms and a culture of shame related to disclosure, which in turn leads to impunity. Participants passively pointed to the culture of silence and stigmatisation of victims as explanations for the lack of reporting.

Participants spoke of gender inequality through statements on forced marriage, lack of consent, the socialisation of girls to be passive and meek, and the culture of aggressive masculinity. Several participants noted that there is really no such thing as girls or women being able to decline sexual advances; thus denouncing sexual acts as violent or of having an outside court determine violence becomes difficult and complex.

Although marginalised groups such as women often have pockets of agency that can lead to organised social movements, important factors must be in place to allow for collective action (Novelli 2010; Weldon and Htun 2013). For example, the recent global \#MeToo campaign involves breaking silence and denouncing perpetrators to hold them responsible. However, this has elements which are yet to be seen in Burkina Faso and Benin: a privileged class willing to continually and sustainably speak out (Novelli 2010), long-term activists and legacies of women's movements (Weldon and Htun 2013), building steps toward collective action with an increased critical mass of opposition, and friendly international media sources that support the movement (Jaffe 2018). 
This suggests that these two countries may not yet be ready for a movement that mirrors exactly what has been seen from \#MeToo globally (loussouf 2018). Thus far, grass-roots elements have not been able to build sustained action nor have individuals in positions of power broken the veil of silence around SGBV in schools, likely due to fear of retaliation. This is supported by recent research that demonstrates that familial, social, and political pressure often prevents perpetrators from being held accountable, as a result of bribes to implementing actors responsible for accountability, within the country contexts of Benin and Burkina Faso (Hughes 2017). As a result, the phenomenon is likely to continue, along with maintaining the strict code of collective silence in order to preserve cultural norms of saving face and prioritising relationships, and thereby avoiding 'conflict'. This in turn leads to a lack of political will and along with this, financial resources (ibid.) to implement policies against sexual violence or respond to the violence within schools and other institutions.

Furthermore, a crucial part of combating sexual violence is speaking out against it. At all levels of society, participants reported that it is unsafe to disclose information about sexual violence in schools to any type of authority, and so girls and women are expected to learn how to silently build resilience to the trauma so it does not negatively affect her life further. The lack of disclosure, as seen in this study, steeped in cultural shame and stigmatisation, limits what actors feel they can do to assist victims and to hold perpetrators accountable. This results not in collective support against the violence, but a division, created by blame. This blame, deflecting responsibility, allows each person to follow the social norms of silence. A culture of silence stigmatises and shames victims of violence and does not allow a flow of knowledge nor the ability to organise. Thus, there is a cyclical obstacle to allowing a critical mass to form that would create some protection for those denouncing perpetrators, and instead allowing impunity for those complicit in the violence.

\section{Pockets of resistance}

Despite the lack of elements needed for breaking down norms around SGBV, there are pockets of organisation and resistance that are demanding general accountability and transparency in both countries. For example, in Burkina Faso, a few grass-roots associations created by women, such as APEFF, have started to confront the silence around violence and the stigma against victims. The women have been subjected to death threats for their courage to speak out against violence against women and for maintaining attention to this issue within their community. However, their impact has been limited to their local community. They speak of using social norms to protect victims and shame perpetrators. Rather than promote accountability using official state systems such as the police, justice system, or social services, APEFF works with the schools and families to negotiate 
compromises. However, this action, in itself, should be seen as a pocket of resistance, as the women are confronting acts that are often silently ignored. Larger NGOs and INGOs could work with APEFF in order to implement a response in a more formal way as well as to help other local communities organise in a similar way in order to respond to violence at the school level.

In Benin, the emergence of the 2006 anti-sexual harassment legislation was the beginning of collective action, with the support of INGOs and NGOs. Moreover, steeped in Beninese revolutionary history of the 1970s, committed female activists have continued to spread awareness about preventing pregnancy, preventing school dropouts, and sharing information on sexual violence through women's organisations such as WiLDAF and the West Africa Network for Peacebuilding (WANEP) (La Nouvelle Tribune 2018a). There has also been the emergence of sanctions against teachers responsible for getting female students pregnant, including ending their contracts (Houngbadji 2018). Moreover, university students have begun to organise protests against violence within schools and unfair practices (La Nouvelle Tribune 2018b).

Although there are currently limits to achieving accountability due to entrenched oppression, norms of silence, and the lack of a powerful grass-roots women's movement to address sexual harassment in schools, the collective action presents emerging possibilities. Participants exhibit hope and confidence in these actions when discussing ways to mitigate sexual violence in schools. The emergence and sustained work of women-led grass-roots organisations and other forms of collaborative resistance is encouraging, though thus far their ability to disrupt the norms around sexual violence in schools and demand accountability has been limited in both countries. This could, however, be the starting place for a movement to grow in the future.

\section{Learning beyond context}

It is clear that existing policies and responses are not having the desired impact on stymieing SGBV or holding perpetrators accountable. International development and INGO pressure is limited, and as a result, social norms in local contexts remain powerful. This demonstrates the importance of investing in institutions of response, building knowledge and understandings related to social norms, involving multiple levels of society in responding to sexual violence, and sustaining grass-roots movements.

Building on current global movements against sexual violence, revolutionary tendencies towards improving democracy, and organising for change provides a baseline that suggests the possibility of honouring communitarian African society with a focus on collective wellbeing (Cobbah 1987; Phillips 2006). An integrated approach from multiple sectors of society could 
be applied to respond to and prevent sexual harassment and violence against girls in schools and enforce accountability through checks and balances. This would embrace collective and holistic action, targeting violence and response in homes, schools, and neighbourhoods; shifting the level of analysis from individuals to collectives and directing more effective research to prevention efforts (Chan et al. 2016; Cowie and Dawn 2007b). This is also aligned with the recognition that an ecological approach to violence prevention is needed in order to create system-wide change, which contributes to both individual and collective wellbeing in reducing violence, targeting shame and stigma, and going beyond law and policy change (Chan et al. 2016). This approach also suggests that it is not one single level of stakeholders which will be responsible for responding to sexual violence or holding perpetrators accountable, but rather a coherent system of programmes and interventions that complement, instead of duplicate one another, and push towards a long-term paradigm shift (Burton 2008). This could apply to other contexts outside of Benin and Burkina Faso, particularly in the Francophone West African context, which may have similar dynamics.

\section{Conclusions}

This article highlights the intersecting relationship of multiple contexts within society, such as family, community, school leadership, educators, and institutions, when responding to sexual violence and harassment in schools. It illustrates obstacles hindering collective responsibility, the beginnings of collective action, and the possibilities for more sustainable collective action and accountability through combating oppression and working towards interdependent responsibility and collective work. The limited attention to entrenched gender dynamics, obstacles with disclosure, shame, and stigma, along with lack of enforcement of reporting mechanisms, have meant these layers are ignored when holding perpetrators accountable. A wholeschool, multi-sector, communitarian approach raises possibilities for a contextually specific response that is holistic in its intention towards community and survivor wellbeing.

At a policy level, this research raises questions about the ability of law or policy to be implemented in an environment that often ignores the societal culture that creates barriers for the compliance of laws. Laws in place to hold perpetrators accountable are often vague or not enforced. There are no laws that tackle the norms of handling things privately, which are upheld by cultural and social norms and the lack of structured reporting mechanisms. The suggested collective approach may provide the opportunity to create checks and balances to ensure accountability is placed at the forefront, and that collective action is possible. 
Moving forward, there is a need to better incorporate the voices of students, teachers, and parents, of which the government, INGO, and NGO representatives spoke about within this study. Additionally, a deeper analysis is needed to investigate the limited resources and levels of poverty that may encourage sexual violence and exploitation in schools and prevent response.

\section{Notes}

* This issue of the IDS Bulletin was prepared as part of Action for Empowerment and Accountability (A4EA), an international research programme exploring social and political action in fragile, conflict, and violent settings. A4EA is a consortium led by IDS and funded with UK aid from the UK government (Foreign, Commonwealth and Development Office - FCDO). The views expressed do not necessarily reflect the official policies of IDS or the UK government.

+ Ms Steiner would like to thank the Center for African Studies at Rutgers University for their Graduate Enrichment Grant and the Rutgers University Graduate School Pre-Dissertation Award for their generous funding towards this research. Ms Spear would like to thank the West African Research Association (WARA) Pre-Doctoral Fellowship programme for support of her research.

1 Jordan J. Steiner, PhD candidate, Rutgers University, USA.

2 Anne M. Spear, researcher and consultant, University of Maryland (International Education Policy Program), USA.

\section{References}

Akpo, M. (2008) 'Combating Gender-Based Violence in Benin', in M. Tembon and L. Fort (eds), Girls' Education in the 21st Century: Gender Equality, Empowerment and Economic Growth, Washington DC: World Bank

Antonowicz, L. (2010) Too Often in Silence: A Report on SchoolBased Violence in West and Central Africa, Senegal: UNICEF, Plan West Africa, Save the Children Sweden West Africa and ActionAid (accessed 2 September 2019)

Arnoff, E.; Hill, L.; Bloom, S.S. and Maman, S. (2013) The Women's Justice and Empowerment Initiative: Lessons Learned and Implications for Gender-Based Violence in Sub-Saharan Africa, Technical Report, Chapel Hill NC: MEASURE Evaluation

Burton, P. (2008) Dealing with School Violence in South Africa, CJCP Issue Paper 4, Claremont: Centre for Justice and Crime Prevention

CDC (2015) The Social-Ecological Model: A Framework for Prevention, Atlanta GA: Centers for Disease Control and Prevention (accessed 15 January 2020)

Chan, W.Y.; Hollingsworth, M.A.; Espelage, D.L. and Mitchell, K.J. (2016) 'Preventing Violence in Context: The Importance of Culture for Implementing Systemic Change', Psychology of Violence 6.1: 22-26

Cobbah, J. (1987) 'African Values and the Human Rights Debate: An African Perspective', Human Rights Quarterly 9.3: 309-31 
Cowie, H. and Dawn, J. (2007a) 'Understanding School Violence', in H. Cowie and J. Dawn (eds), Managing Violence in Schools: A Whole-School Approach to Best Practice, London: Sage Cowie, H. and Dawn, J. (2007b) 'Working with the Whole School Community', in H. Cowie and J. Dawn (eds), Managing Violence in Schools: A Whole-School Approach to Best Practice, London: Sage

Devers, M.; Henry, P.E.; Hofmann, E. and Banabdallah, H. (2012) Gender-Based Violence at School in French-Speaking Sub-Saharan Africa: Understanding its Impact on Girls' School Attendance to Combat it More Effectively, République Francaise: Ministère des Affaires Étrangères

Diawara, A.T.; Compaoré, M.; De Cecco, L. and Rouamba, O.K-Z. (2013) Etude Sur les Grossesses Non Desirees et les Cas D'Evanouissement des Jeunes Filles en Milieu Scolaire [Study on Unwanted Pregnancy and the Case of Evaluation of Girls in Schools], Ouagadougou: Initiatives Conseil International

Dunne, M.; Humphreys, S. and Leach, F. (2006) 'Gender Violence in Schools in the Developing World', Gender and Education 18.1: 75-98

Forsyth-Queen, E.; Gonzalez, L. and Meehan, S. (2015) 'Doorways: Preventing and Responding to School-Related, Gender-Based Violence in West Africa', in S.L. Stacki and S. Baily (eds), Educating Adolescent Girls Around the Globe: Challenges and Opportunities, New York NY: Routledge

Government of Burkina Faso (2012) 'Strategie Nationale D'Acceleration de L'Education des Filles (SNAEF) (2012-2021)', [National Strategy for the Acceleration of Girls' Education], Ouagadougou: Government of Burkina Faso

Houngbadji, C. (2018) 'Bénin - Grossesses en Milieu Scolaire: Élèves et Professeurs Auteurs', En Conseil de Discipline, 6 June (accessed 15 January 2020)

Hughes, C. (2017) Legislative Wins, Broken Promises: Gaps in Implementation of Laws on Violence Against Women and Girls, Oxfam Research Reports, Oxford: Oxfam (accessed 19 December 2019)

loussouf, R. (2018) 'Why \#MeToo Isn't Taking Off in West Africa', BBC News, 3 February (accessed 6 August 2018)

Jaffe, S. (2018) 'The Collective Power of \#MeToo', Dissent Magazine (accessed 6 August 2018)

La Nouvelle Tribune (2018a) 'Bénin: Lutte Contre le Harcèlement Sexuel et Les Grossesses Précoces en Milieu Scolaire', 8 February (accessed 15 January 2020)

La Nouvelle Tribune (2018b) 'UAC - Bénin: La Grève Largement Suivie par les Etudiants', 14 February (accessed 6 August 2018)

Lee, V.E.; Croninger, R.G.; Linn, E. and Chen, X. (1996) 'The Culture of Sexual Harassment in Secondary Schools', American Educational Research Journal 33.2: 383-417

McCleary-Sills, J. et al. (2016) 'Stigma, Shame and Women's Limited Agency in Help-Seeking for Intimate Partner Violence', Global Public Health 11.1-2: 224-35 
Meinck, F.; Cluver, L.D.; Boyes, M.E. and Mhlongo, E.L. (2015) 'Risk and Protective Factors for Physical and Sexual Abuse of Children and Adolescents in Africa: A Review and Implications for Practice', Trauma, Violence, and Abuse 16.1: 81-107

Novelli, M. (2010) 'Learning to Win: Exploring Knowledge and Strategy Development in Anti-Privatization Struggles in Colombia', in A. Choudry and D. Kapoor (eds), Learning from the Ground Up: Global Perspectives on Social Movements and Knowledge Production, New York NY: Palgrave Macmillan

Phillips, L. (ed.) (2006) The Womanist Reader, New York NY: Routledge

République du Bénin Assemblée Nationale (2012) 'Loi \# 2011-26 du 9 Janvier 2012 Portant Prévention et Répression des Violences Faites aux Femmes', Republic of Benin, New York NY: UN Women (accessed 10 January 2020)

République du Bénin Assemblée Nationale (2006) 'Loi \# 2006-19: Portant Répression du Harcèlement Sexual et Protection des Victimes en République du Bénin', Republic of Benin, Geneva: International Labour Organization (accessed 10 January 2020)

Séne, K.N. (2010) 'The Politics of Female Adolescent Sexuality: Perceptions, Conceptualizations and Experiences of Transactional Teacher-Student Sexual Relationships in Northern Beninois Secondary Schools', unpublished master's dissertation, Centre for International Studies, Ohio University

Spear, A.M. (2018) 'What About the Grassroots Leaders? A Model for Culturally Appropriate Leadership through Empowering Local Women', in R.J. Thompson and J. Storberg-Walker (eds), Leadership and Power in International Development: Navigating the Intersections of Gender, Culture, Context, and Sustainability, Bingley: Emerald Publishing

UN General Assembly (1993) Declaration on the Elimination of Violence against Women, 20 December, A/RES/48/104 (accessed 14 January 2020)

UNGEI (2018) A Whole School Approach to Prevent School-Related Gender-Based Violence, Minimum Standards and Monitoring Framework, New York NY: United Nations Girls' Education Initiative (accessed 19 December 2019)

Weldon, S.L. and Htun, M. (2013) 'Feminist Mobilization and Progressive Policy Change: Why Governments Take Action to Combat Violence Against Women', Gender \& Development 21.2: 231-47

WHO (2002) World Report on Violence and Health, Geneva: World Health Organization

Wible, B. (2004) Making School Safe for Girls: Combating Gender-Based Violence in Benin, Washington DC: Academy for Educational Development

Zare, W.K.; Yaro, Y. and Dan-Koma, I.M. (2008) Background Study of the Inter-Agency Joint Programme on Violence Against Women: Burkina Faso (accessed 11 August 2018) 
